\title{
SOBRE EL TERRITORIO: PRÁCTICAS ARTÍSTICAS SOCIALMENTE COMPROMETIDAS
}

\author{
María Luisa Sobrino Manzanares \\ Universidade de Santiago de Compostela
}

ORCID: https://orcid.org/0000-0002-8399-3436

\section{RESUMEN}

Frente a las consideraciones tradicionales, el nuevo género de arte público supone una alteración de los planteamientos formales anteriores y de las respectivas referencias al lugar. Implicado en indagar y participar en motivaciones y situaciones sociales, se sitúa más allá de cualquier aspecto de lo que tradicionalmente se entendía como arte y, especialmente, de toda noción convencional referente a la idea de escultura pública. Nuevas propuestas que cambian de modo radical la idea de arte en el espacio urbano porque ya no pretenden ser referencia física, señalamiento o diálogo con el medio, sino un elemento de confrontación ciudadana, integrante y compartido por la comunidad en la que se asienta. Desde esta perspectiva, mi propuesta se centra, especialmente, en la obra de Carme Nogueira, una de las artistas más representativas dentro de la tendencia de un cuestionamiento crítico sobre el espacio público.

Palabras clave: arte público, territorio, dimensión social, ciudadanía, lugares de tránsito, memoria, interdisciplinaridad

\section{ABSTRACT}

In contrast to traditionally held views, the new genre of public art represents a variation on the formal approaches of the past and the respective references to place. Concerned with investigating and participating in social motivations and situations, it takes up a position outwith what is traditionally understood as art and, in particular, any conventional notion referring to the idea of public sculpture. These new proposals radically alter the idea of art in the urban space as they do not seek to be a physical reference, signal or dialogue with the environment but an integrating component of public confrontation, shared by the community in which it is located. Based on this perspective, my proposal is essentially focused on the work of Carme Nogueira, one of the most representative artists of a trend that lends a critical eye to the public space.

Keywords: public art, territory, social dimension, citizenry, places of transit, memory, interdisciplinarity

El arte-dice Marcuse - rompe la experiencia del día a día y participa de una realidad diferente... expresa una conciencia de crisis: un placer en decadencia, en destrucción, en la belleza diabólica, una celebración de lo asocial, de lo anónimo - la revolución secreta de la burguesía contra su propia clase. Marcuse, H., The Aesthetic Dimension. Boston: Beacon Press, 1979
Desde que se publicó el libro Escultura contemporánea en el espacio urbano. Transformaciones, ubicaciones y recepción pública', han variado notablemente las formas y los planteamientos que, referidos a este tema, se apuntaban en las prácticas artísticas desde finales del siglo pasado. Si bien se siguen celebrando convocatorias internacionales sobre arte público -desde la más 
veterana Skulptur Projekte de Münster hasta la más reciente KölnSkulture en Colonia-, se trata de proyectos concebidos para determinados espacios de representación -parques, paisajes naturales o ámbitos urbanos- y para determinados espacios temporales. Eventos donde se reúnen instalaciones y esculturas que responden más a la idea de un arte público en diálogo con los ámbitos propuestos y con las diferentes ubicaciones que, dentro de esos recintos, son elegidos por los artistas para realizar sus intervenciones.

Y aunque en este libro, publicado en 1999, se apuntaba en el último capítulo un arte público que adopta un matiz socialmente cada vez más comprometido, a medida que transcurren las nuevas décadas del segundo milenio, se observa una alteración de los aspectos que definen el arte público anterior y de las respectivas referencias del lugar. Se trata de dirigir, indagar y participar en motivaciones y situaciones sociales, más allá de cualquier aspecto de lo que tradicionalmente se entendía como arte y, especialmente, de toda noción convencional referente a la idea de escultura pública. Nuevas propuestas que cambian de modo radical la idea de arte público en su intervención en el espacio urbano, que ya no pretenden ser referencia física, señalamiento o diálogo con el medio, sino un elemento de confrontación ciudadana, integrante y compartido por la comunidad en la que se asienta².

Nuevas definiciones nos llevan a considerar el nuevo género de arte público -según opinión de Marta Ferrán- como "un arte de su tiempo, comprometido con el lugar en que se produce. Son sus particularidades: la dimensión social, económica y política y una transformación del artista como agente aislado que supera la concepción tradicional, desmitificando el culto al creador (...). Traspasar el arte de concepto, al arte de contexto, es avanzar y reconocer la densidad formal de toda obra pero también la dimensión social y relacional, propiedades inherentes al arte público" ${ }^{3}$.

La apertura de prácticas llevadas a cabo en este contexto de arte público, muestra actualmente multitud de posturas divergentes. Un amplio abanico que abarca desde el asociacionismo cultural y vecinal que indaga en la memoria histórica, hasta movimientos sociales radicales de un activismo político militante y de desobediencia civil. Con- siderados por unos como lugares de "espacialidad disidente", ${ }^{4}$ "lugares de protesta o espacios de asociación alternativos" 5 , o por otros como "okupaciones" del espacio público. En algunos casos son acciones protagonizadas por colectivos contraculturales que intentan desenvolver unos cometidos en función de las particularidades de la experimentación social, de la creatividad y de la historia del lugar, o "del derecho a la ocupación de un espacio sin colonizar -para las casas, para los árboles, para reunirse, para bailar" ${ }^{\prime}$.

En todo caso, los nuevos planteamientos del arte público desafían las convicciones de las funciones del arte: difuminan la oposición de los principios establecidos entre lo privado y lo público por una inherente interacción entre ambos ámbitos. Poseen un carácter temporal y efímero, adecuándose a la fugacidad, algo que aunque es propio de lo urbano actual, nada tiene que ver con el deseo tradicional de permanencia del arte público. Sus posturas, podrían definirse como subversivas y críticas, "arte socialmente comprometido", -como lo denomina la ensayista Sophie Hope-, 7 ajeno a cualquier tipo de encargo público o de gerentes urbanos.

Basándose en una serie de artistas -entre los que Sophie Hope destaca a Susan Lacy-, la misma autora establece varios estadios del proceso creativo, capaces de sintetizarse del siguiente modo: Desde una primera experimentación donde el artista, como un antropólogo subjetivo, entra en el territorio del Otro y hace observaciones sobre la gente y los lugares a través de un relato de su propia interioridad. Durante este primer paso, la prioridad para el artista es la investigación y la recopilación de material sobre una comunidad dada (...) Tomando la posición de un observador distante, el artista es capaz de sacarnos de la complacencia perceptiva, para forzarnos a ver un mundo distinto fuera de las fronteras familiares del lenguaje común y de los modos existentes de representación. Cuestiones que están ahí desde siempre pero que los sistemas de representación espacial convencional no asumen.

Para Susan Lacy, cada artista se convierte en un analista que comienza a investigar las situaciones sociales a través de su arte, asumiendo por él mismo capacidades más comúnmente asociadas a científicos sociales, geógrafos, antropólogos, 


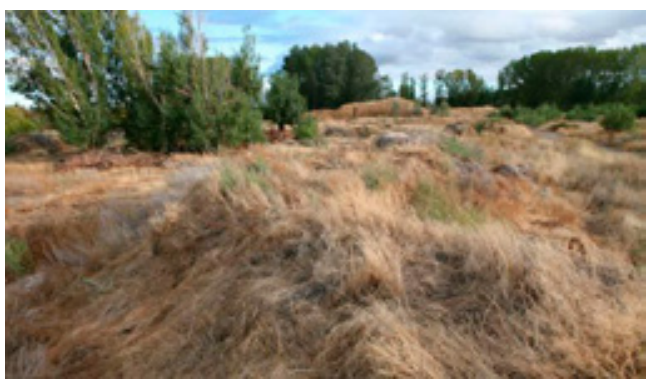

Fig. 1. Lara Almarcegui. Parque fluvial abandonado

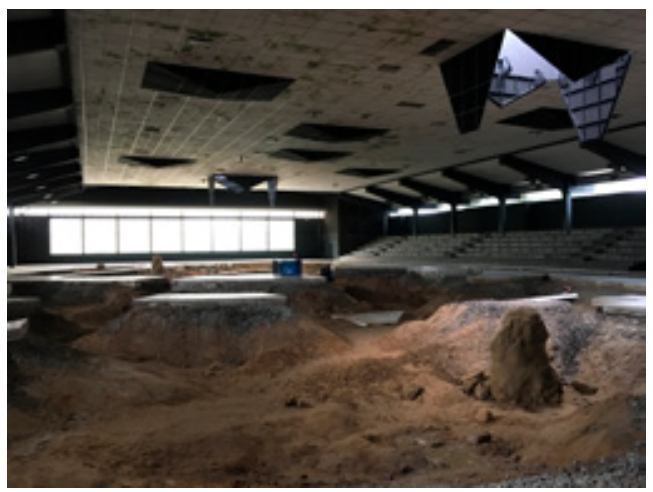

Fig. 2. Pierre Huygue. After Alife Ahead. Münster Skultur Projekte, 2017

periodistas de investigación o sociólogos. Trabajos que no son considerados únicamente como elementos estéticos, suprimen toda gratificación visual, pero que por el contrario suponen una implicación social y el trabajo compartido de la comunidads.

Dentro del conjunto de creadores activistas que intervienen en espacios urbanos, el presente texto pretende mostrar un tipo de arte aplicado a espacios alternativos de la ciudad dominante y a otras posibilidades interpretativas de los pasajes ocupacionales y sociales del espacio público. Una nueva comprensión de los vínculos entre estética, antropología y política llevada a cabo por autores de distintas procedencias que no caminan en sincronía ni en semejanza los unos con los otros, pero que plantean maniobras socialmente comprometidas en trabajos performáticos e interactivos sobre el territorio. Me propongo hacerlo a través de tres autores, destacando especialmente la obra de Carme Nogueira pero, en todo caso, estas propuestas de arte público se basan esencialmente en la intervención en el suelo y

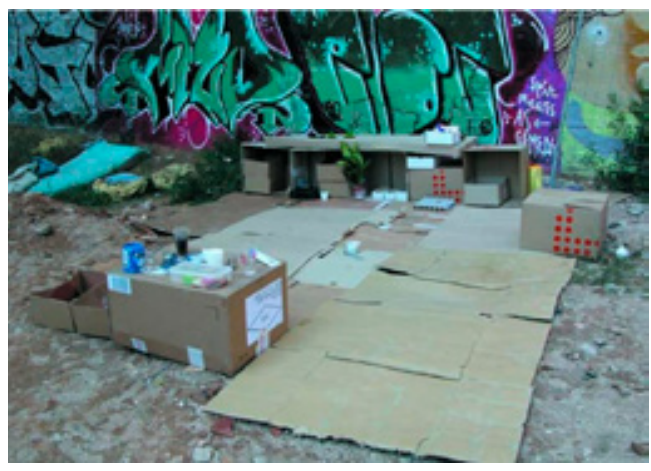

Fig. 3. Carme Nogueira. Site especific Metronom, 2006

en su historia. Interpretan el paisaje como una construcción social o simplemente originaria y lo conciben como extensión del patrimonio cultural y su interpretación.

Para unos, como Lara Almarcegui (fig. 1), "el arte se configura como un artificio para preservar el abandono y hacer avanzar la ruina. La naturaleza, aliada con el tiempo, se encarga de crear la obra"9. Para otros, como en la reciente obra de Pierre Huygue en Münster (fig. 2), se establece como una excavación antropológica que conduce a la entropía o, como en Carme Nogueira (fig. $3)$, se define en los contextos abandonados/marginados de la ciudad, activando con elementos discursivos esos retazos de una memoria social casi siempre conflictiva.

Los artistas que aquí nos ocupan trabajan en proyectos de ocupación temporal, creando en esos espacios un uso diferente que recae sobre todo en el acto en sí, en la performance. Son intervenciones en tierras de nadie, zonas en permanente estado de indefinición, de discontinuidad y residuo en los mapas institucionales, pero lugares connotados ideológicamente a pesar de su apariencia neutra10. "Los solares desocupados son un tipo especial de espacio de tránsito, son espacios de transición solo temporalmente ya que pertenecen a alguien y tienen una función predeterminada. Pero al mismo tiempo su carácter transitorio abre posibilidades a otra comprensión no sólo de ese espacio sino del contexto y la circulación urbana en general. Las acciones que en ellos se realicen no pretenden un arraigo. "Y es quizá la falta de arraigo lo que abre más posibilidades a otra comprensión del espacio"11. 


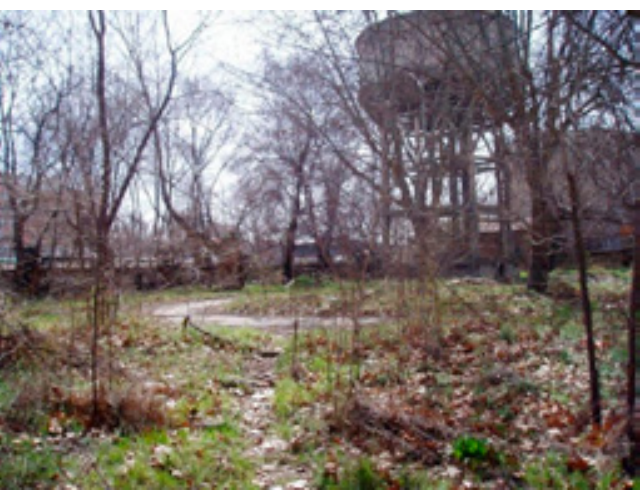

Fig. 4. Lara Almarcegui. Descampado del Matadero, Madrid, 2005-2006

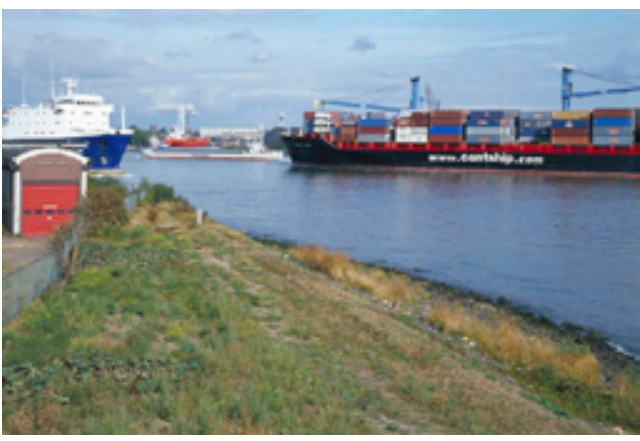

Fig. 5. Lara Almarcegui. Descampado en el puerto de Rotterdam, 2013-2018

\section{Cuando el abandono se transforma en arte}

Lara Almarcegui trabaja sobre estos espacios de transición, abiertos y vacios, que evidencian las contradicciones urbanas. Como señala Julia Ramírez Blanco, "de su trabajo se desprende una fascinación por los procesos de desaparición arquitectónica y sus legados materiales: demoliciones, ruinas, escombros" (fig. 4). Un interés que se caracteriza por un urbanismo anarquista y radical de esos espacios como lugares libres de planificación, sin nada que los altere, partes del espacio público excluidas y olvidadas de la correcta y normalizada urbanidad (fig. 5). "Debido a su aislamiento, los descampados son espacios naturales privilegiados convertidos en islas dentro de la ciudad donde la naturaleza se desarrolla a su aire donde todo sucede al azar sin ningún plan determinado -escribe Lara Almarcegui- a propósito del proyecto sobre el gran descampa-

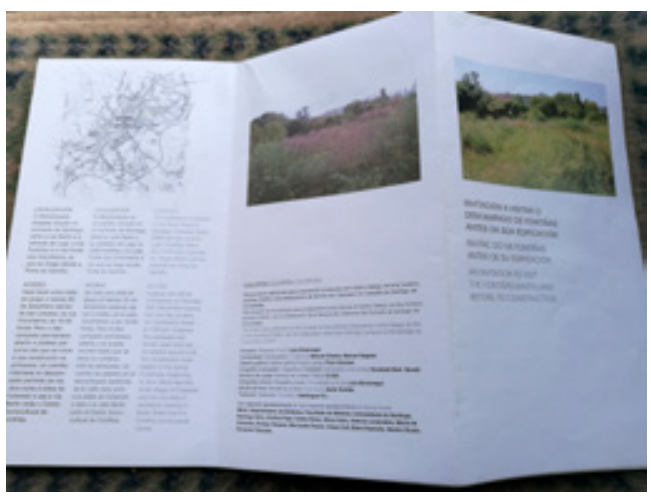

Fig. 6. Tríptico editado por CGAC. Descampado Fontiñas, Santiago de Compostela, 2017

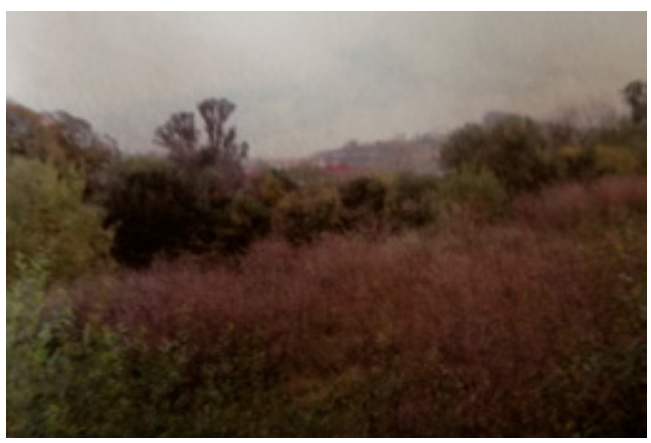

Fig. 7. Lara Almarcegui. Brañas. Descampado Fontiñas, Santiago de Compostela, 2007

do situado en la zona de Fontiñas en Santiago de Compostela, a punto de desaparecer para ser urbanizado y construido ${ }^{12}$. Todo en ellos es posible -añade- y todo se puede esperar, cuando son presentados al espectador con la intención de que sea apreciado de una manera distinta.

Como haría en otros lugares con intervenciones parecidas, como Lisboa, Roma, Amsterdam, con motivo de este proyecto en Compostela se editaría un folleto o guía (fig. 6) compuesto de pequeños textos descriptivos y fotografías de la autora, (fig. 7) además de un gran mapa en el que se muestra la rotulación de los terrenos huertas privadas, caminos, arroyos, regatos, ruinas, etc., con el objetivo de documentar y dejar constancia de la orografía y ecosistema inherente al habitat original, a su vegetación autóctona, como un espacio libre y silvestre antes de su diseño urbanístico (fig. 8). El empleo de estas guías "es el resultado de una esmerada investigación acerca de cada solar, narrándonos la historia de 


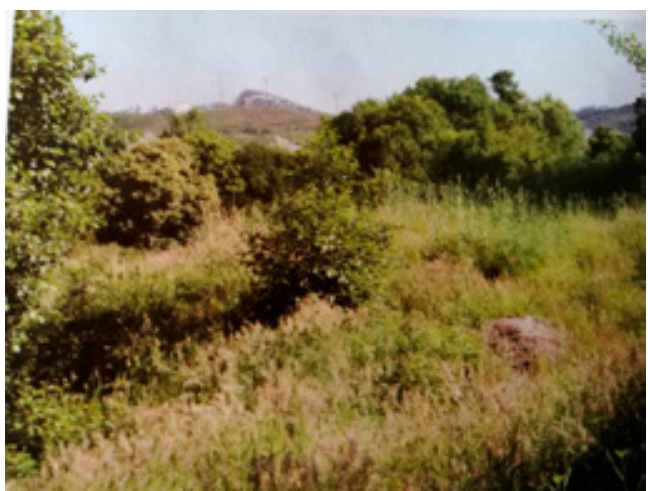

Fig. 8. Lara Almarcegui. Brañas. Descampado Fontiñas, Santiago de Compostela, 2007

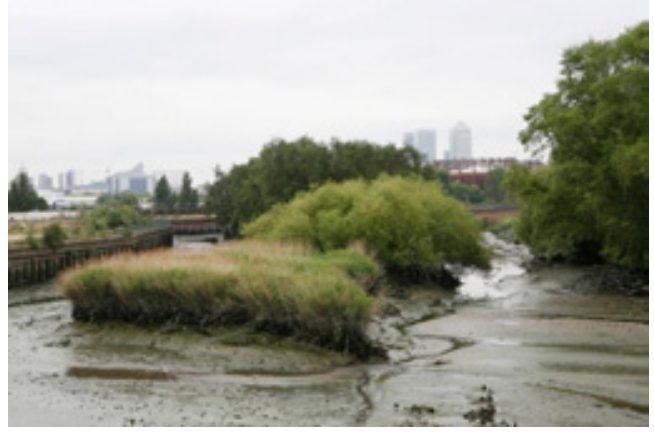

Fig. 9. Lara Almarcegui. Descampado Río Lea, 2009

cada parcela enunciándonos los distintos usos que han tenido por sus antiguos y sus nuevos propietarios a lo largo del tiempo"13.

La preservación de estos lugares, generalmente condenados a una desaparición rápida (fig. 9) la ruptura de barreras que los limitan para incorporarlos al espacio público, el conseguir su mantenimiento sin urbanizar -sean de propiedad privado o de administración pública-, caracteriza el trabajo de Almarcegui (fig. 10). Es un arte en el terreno de la negociación relacionado con un continuo social y tanto con la estética artística como con la responsabilidad ética. A través de cesiones en préstamo, lo que supone negociaciones y convenios, este propósito de trazas casi utópicas "no está concebido con un fin social, sino que los entiende como espacios cuya existencia misma resulta primordial al margen de cualquier utilidad posible. Aunque permanecen abiertos, el grado de accesibilidad de los solares varía según las peculiaridades de cada uno (fig. 11).

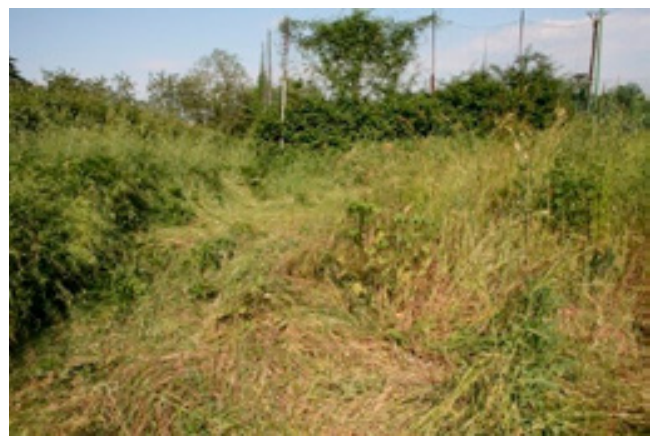

Fig. 10. Lara Almarcegui. Descampado en Roma, 2007

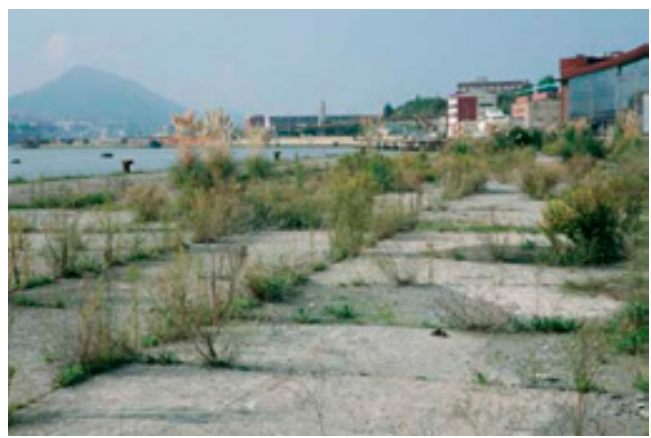

Fig. 11. Lara Almarcegui. Descampado Ría de Bilbao, 2014

Como señala Carme Nogueira, estos terrain vagues son lugares idóneos para incitar la creatividad y la imaginación, proporcionan nuevas lecturas del lugar visualizando cuestiones antes ocultas, estrategias de ocupación que -en palabras de Manuel Segade- originan una memoria, una sustancia en el espacio que produce nuevas estructuras, otros modos de vida no legitimados por el poder o la posibilidad de otras formas de hacer ${ }^{14}$. En todo caso, ese "contexto" se introduce como parte de la propia obra, es su site specific, la pertinencia del lugar, en el que se utiliza la representación como puesta en escena: la obra de arte como performativo lugar de interpretaciones abiertas donde el espectador pueda ser el agente que ordene sus propias interpretaciones.

El sentido de transición temporal puede verse además a través de las múltiples capas históricas del suelo. Las ruinas halladas en el subsuelo, las construcciones que rodean el solar y las implicaciones de sus funciones futuras son momentos históricos que se contraponen o dialogan. Hablan de un uso diferente del suelo, basado en la per- 


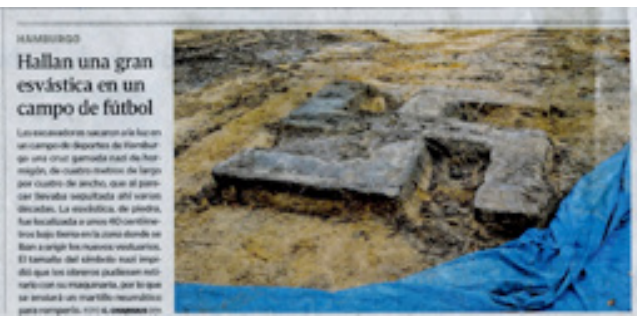

Fig. 12. La Voz de Galicia, enero 2018

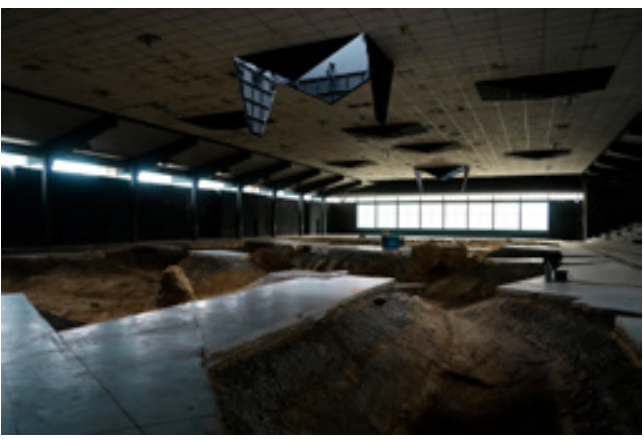

Fig. 13. Pierre Huygue. After Alife Ahead. Münster Skultur Projekte, 2017

manencia, en las huellas históricas vividas y por vivir, en el inevitable arraigo que se instala entre su pasado y su presente (fig. 12).

Una reflexión cuyo principal precedente es sin duda la significativa contribución creativa de Robert Smithson, una de las referencias indispensables de la producción cultural y artística de este campo del arte. Su aportación teórica, su apreciación de lugares poco valorados, el acompañamiento de documentación de mapas, guías y videos avanzó una aprensión del paisaje bajo los nuevos paradigmas de interpretación de las prácticas antropológicas, estéticas y críticas que serán fundamentales en el futuro del arte y la arquitectura.

El sentido que Smithson da a la entropía, latente en la evolución de la naturaleza en las parcelas de Lara Almarcegui, se hará todavía más acusado en la intervención del artista francés Pierre Huyghe con esa propuesta "apocalíptica" ideada en la reciente instalación para Münster, Skultur Projekte (fig. 13). Se debe advertir que aunque esta forma de trabajo sobre el territorio no es la habitual de este artista, su After ALife Ahead, convierte a una abandonada pista de patinaje sobre hielo de los suburbios de Münster en un espectacular escena-

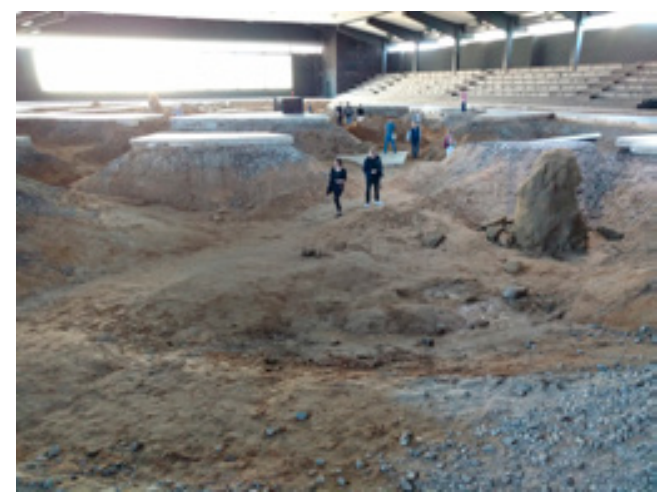

Fig. 14. Pierre Huygue. After Alife Ahead. Münster Skultur Projekte, 2017

rio arqueológico en cuyos ancestrales sedimentos conviven lo inerte con los elementos vivos (fig. 14). A pesar de sus esfuerzos por remarcar todo tipo de cuestiones sociológicas, como opina Enrique Vila-Matas sobre su instalación en Kassel de 2013, "termina por destacar más esas potencias invisibles y sombrías que la propia biogenética de la naturaleza es capaz de producir..."15. En el proyecto de Münster estratifica en una potente excavación las diferentes capas del subsuelo con la que intenta unir presente con pasado, llegar desde el nivel actual hasta la atávica edad del hielo. Perfora el suelo de la pista, donde instala distintos elementos y materialidades que -a manera de escombros o ruinas- generan un paisaje desazonador y de suma rareza. La intervención posee un contenedor donde se reproducen células cancerígenas y estanques que en descomposición y reproducción generan distintas formas de vida como bacterias, algas y abejas. Cada cierto momento, se abren unas compuertas del techo de donde cae la lluvia, generando un paisaje que lleva a una reflexión muy contingente sobre la realidad a la que está sometida la naturaleza (fig. 15).

\section{La experiencia social del territorio}

Dentro de esta perspectiva de interpretación de tentativas sobre el propio territorio, mi propuesta se centra, especialmente, en la obra de Carme Nogueira, una de las artistas más representativas dentro de la tendencia de un cuestionamiento crítico sobre el espacio público. Nacida en Vigo en 1970, estudia Bellas Artes en Salamanca y se doctora en la Universidade de Vigo con una tesis 


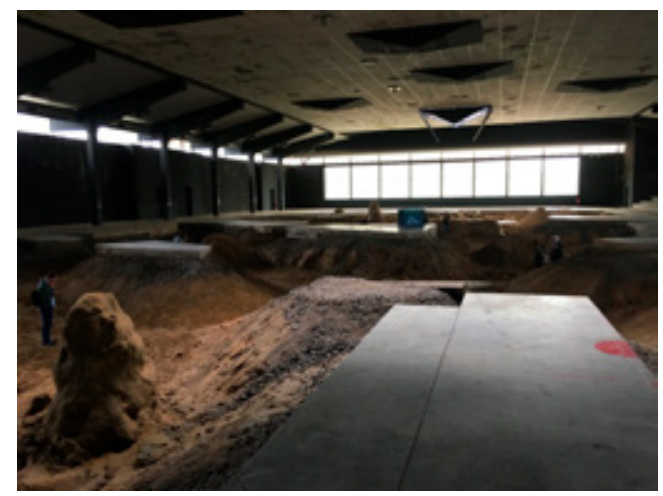

Fig. 15. Pierre Huygue. After Alife Ahead. Münster Skultur Projekte, 2017

doctoral donde analiza el papel del espectador en el arte contemporáneo bajo la perspectiva de la recepción ${ }^{16}$. Ha realizado estancias por toda Europa y sus proyectos alcanzan un nivel internacional, adquiriendo un creciente reconocimiento.

Carme se considera una artista de la realidad cotidiana e indaga como esa vida encierra otras lecturas inapreciables para la ciudadanía. Su sentido del arte como transformación del ámbito usual solo se concibe tras la minuciosa planificación de cada uno de sus proyectos, apoyados en una base documental, investigadora e interdisciplinar sobre los lugares que interviene. Localiza las zonas marginadas de la ciudad o explora un transitar vivencial por los lugares de una historia social "conflictiva" de ciertos pasajes, barrios o determinados lugares de ciudades como Rotterdam, Berlín o París, cuya memoria reconstruye y de los que evoca su pasado y su presente. Una práctica artística -que aunque no rechaza el museo, como son sus intervenciones en el CGAC o en el Museo Marítimo de Valparaiso-, mantiene siempre la misma intención de toda su trayectoria: la activación del espacio público desde una perspectiva crítica.

La elección de cada lugar supone un exhaustivo conocimiento informativo dirigido tanto hacia la dimensión social y antropológica del contexto como a su aspecto comunicativo. Cada proyecto incluye, en su mayoría, una construcción física o visual de la obra, una acción in situ e inseparablemente una profunda reflexión discursiva y conceptual que les da significado. "Desintegra la definición y la práctica del arte no separándola

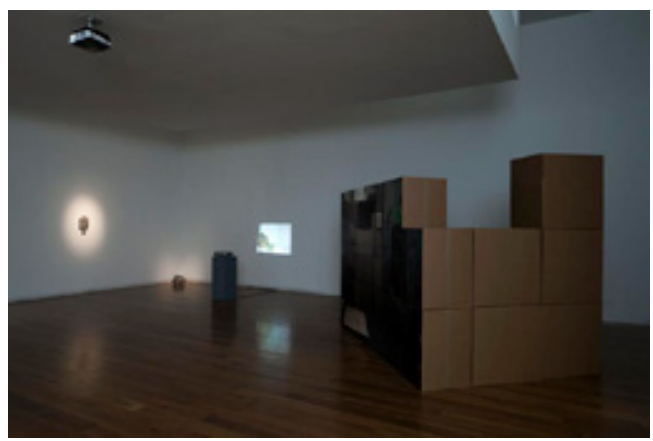

Fig. 16. Carmen Nogueira. Agrupar desagrupar, 2016

ni de la vida ni de la imaginación poética y ligándola a la refundación del compromiso político, enfrentándose a cuestiones sociales puntuales relacionadas con la ciudad y la comunidad" 17 .

Autora de las frágiles estructuras de cartón que ofrecen sus "Refuxios", -parangón de los resguardos de las personas indigentes-, investiga archivos, escucha el relato oral de sus habitantes y rememora las historias, a través de dispositivos de textos en papel o formas tridimensionales, videos, fotografías, literatura de la época, etc.

En la obra de Carme pueden distinguirse dos tipos de actuación: Por una parte, los "Refuxios" -uno de sus elementos más representativos de todo su trabajo-, son concebidos como frágiles dispositivos de cartón que recuerdan los refugios de los sin casa. A modo de recintos a escala humana, estas elementales estructuras metafóricas, que ni encierran ni protegen a posibles habitantes, poseen no sólo un carácter físico sino emocional que nos hacen conscientes de la precariedad de nuestra posición. A través de estas viviendas-cartones, la artista reflexiona sobre una existencia urbana que apuesta por efímeras construcciones infraarquitectónicas e infraurbanas, creadas en todo momento bajo una imaginación poética y un evidente compromiso político.

La importancia de su propuesta radicará en que tiene relación con la visión de un contexto arquitectónico y urbanístico aunque es más cercana a la idea de estructuras que se incorporan al espacio y crecen orgánica y anárquicamente como los alpendres o los galpones de la arquitectura popular, realizados según las necesidades del momento (fig.16). Según ella misma lo describe: "esa forma anárquica de ocupación del espacio 


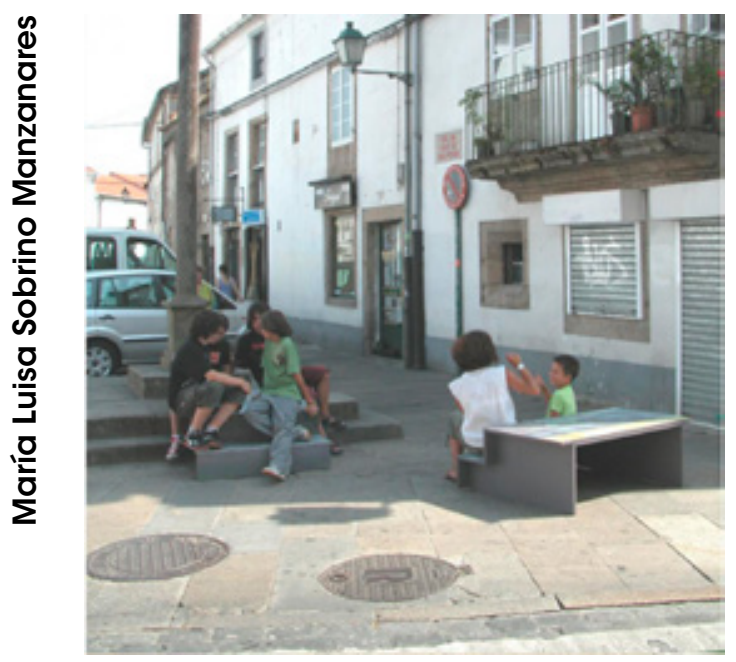

Fig. 17. Carmen Nogueira. ¿Qué facer coas nosas prazas? 2006

no es simplemente una respuesta estética o funcional, significa una forma política de ocupar el espacio, en realidad se trata de una "in-corporación", hacer del espacio parte del cuerpo, que crezca de forma paralela a sus necesidades, de modo orgánico"18. Es una forma de crecimiento anárquico, no regularizada ni ordenada que acaba influyendo en el espacio circundante, de forma que varía su significado. Deconstruye su sentido, transforma el contexto social en que se ubican.

La idea de refugio nos remite también a la creación de espacios exteriores, lugares urbanos de encuentro y participación, ocupados temporalmente por mínimas intervenciones que los hace factibles para poder usarlos, sentirlos como lugares, en los que pueden descansar y conversar los residentes y el vecindario. Con leves acciones a modo de elementales escalones que coloca en determinados lugares -como fue su intervención en el barrio de San Pedro en Santiago de Compostela (fig. 17), o en el conjunto de actuaciones que sitúa en los jardines del Palacio de Cristal de Oporto-(fig. 18), en los que revindica la memoria del lugar como punto de reunión y espacio de la ciudadanía, creando esa sensación de sentirnos libres de usar la palabra y los recuerdos ${ }^{19}$.

Son numerosas las actuaciones en este campo, a pesar del carácter problemático de animación del espacio público. Paralelamente, por la realiza-

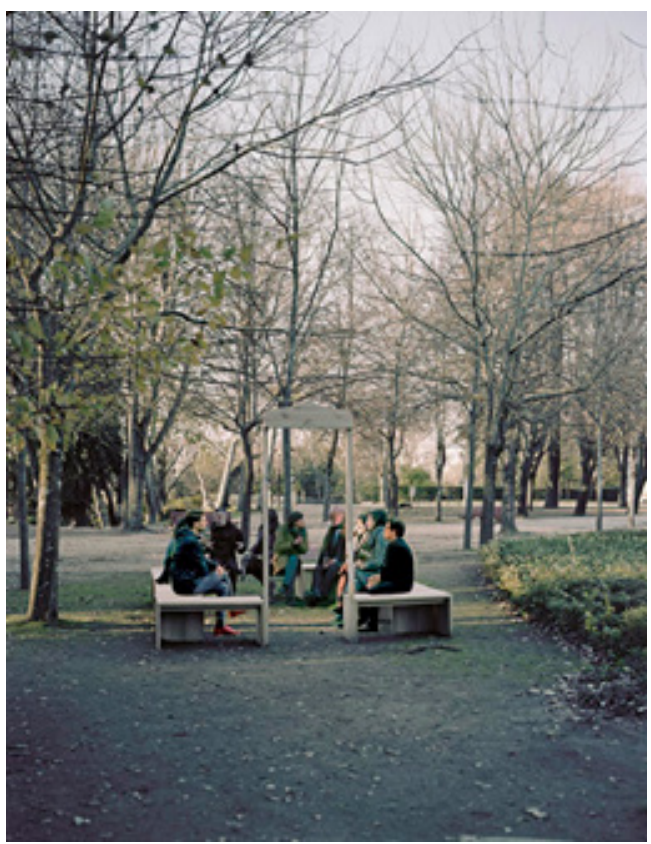

Fig. 18. Carmen Nogueira. A propósito. Jardines Palacio de Cristal de Porto, 2016

ción de trasvases e interacciones entre estas intervenciones urbanas, como site specific, y el interior en la sala de exposición, donde las construcciones de cartón sirven de dispositivo para proyecciones de fotografías o videos, además del empleo de audiovisuales, en los que se reflejan las imágenes exteriores relacionados con la obra. Todo ello se acompaña de una publicación, resultado de la investigación sobre el lugar, textos, fotografías y fragmentos de su historia que complementan y refuerzan el significado de cada uno de sus proyectos. Una interacción que difumina la diferencia entre lo público y lo privado y los convierte en indisoluble unidad. Algo que es característico de toda la obra de Carme, incomprensible sin esa convergencia en cuyo conjunto se configuran cada uno de sus proyectos artísticos.

En este capítulo, sobresale el "Refuxio" instalado en El callejón de Méndez Nuñez, en 2004, realizado para la Galería Ad Hoc de Vigo, una estructura de cartón con puerta de entrada, situado en el callejón al que da a la parte trasera de la sala expositiva (fig. 19). Posteriormente a la intervención del site specific, las mismas cajas que han servido como refugio se usaron en el interior 


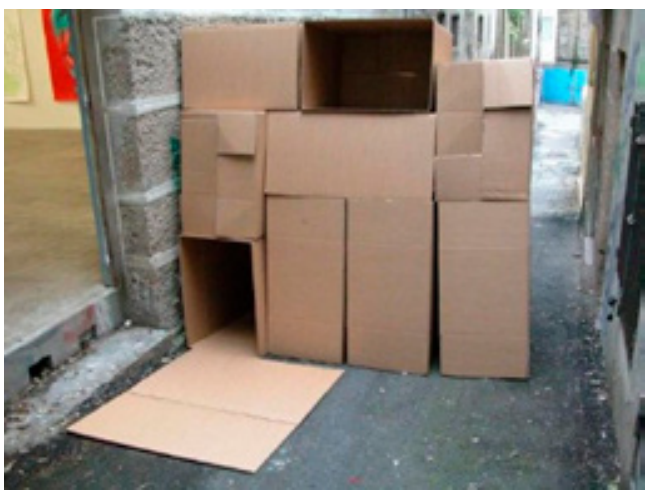

Fig. 19. Carmen Nogueira. Refuxio. Callejón Méndez Núñez, Vigo, 2004

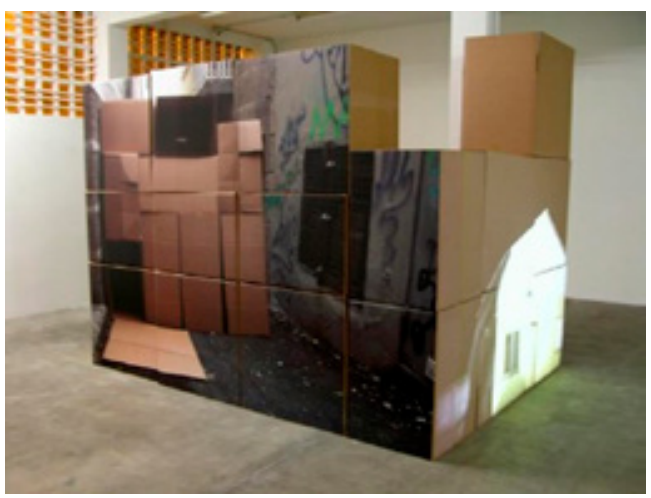

Fig. 20. Carmen Nogueira. Refuxio. Galería Ad Hoc

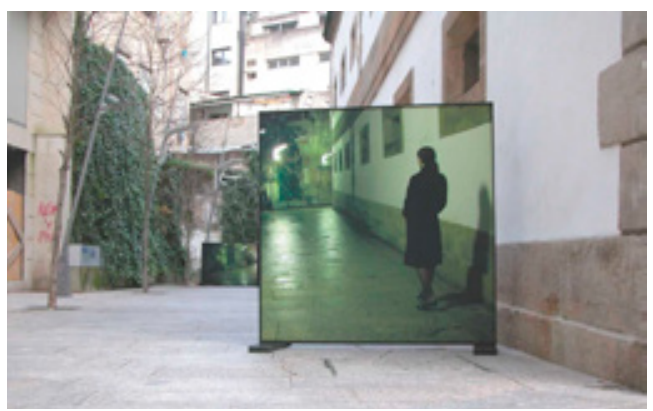

Fig. 21. Carmen Nogueira. Calle Londres. Site especific. Exposición MARCO

de la sala para construir la pieza que presenta en una de sus caras una imagen del refugio externo (fig. 20). Otra de sus caras sirve de pantalla de proyección donde se muestran construcciones reales que actúan como verdaderos refugios en el extrarradio urbano. Un juego exterior-interior que renueva en su intervención en el panópti-

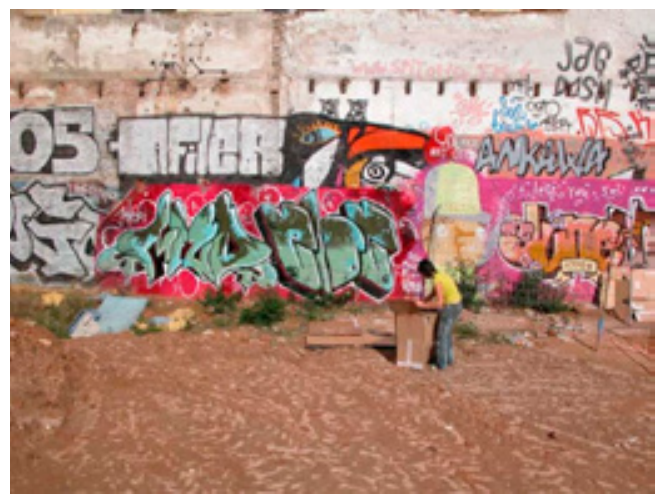

Fig. 22. Carmen Nogueira. Carátula Proyecto Metronom

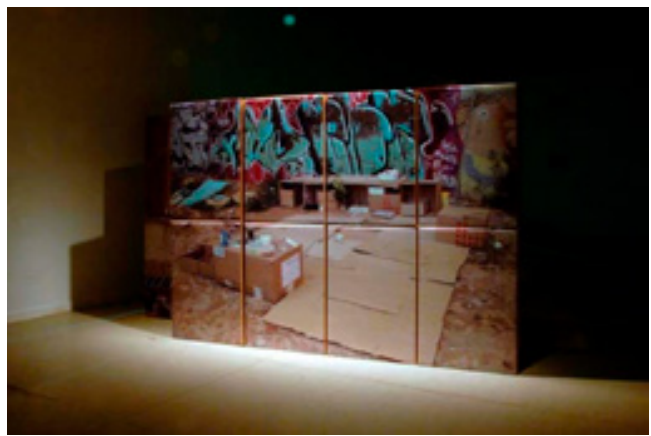

Fig. 23. Carmen Nogueira. Sala Metronom

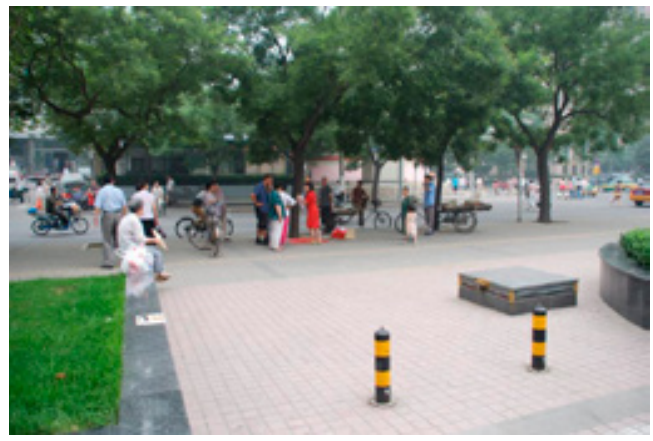

Fig. 24. Carmen Nogueira. Proyecto Próspera Pekín

co del MARCO de Vigo (fig. 21), así como en el conjunto de acciones que realiza en 2006 para Metrónom en Barcelona (figs. 22-23) o el proyecto "Próspera" (2008) en el Instituto Cervantes de Pekín -del que luego realiza una reinterpretación en el Espacio Anexo del MARCO.

En Pekín (fig. 24), impresionada de que las calles en China se usen como extensión del espacio privado, aúna actuaciones y dispositivos sincró- 


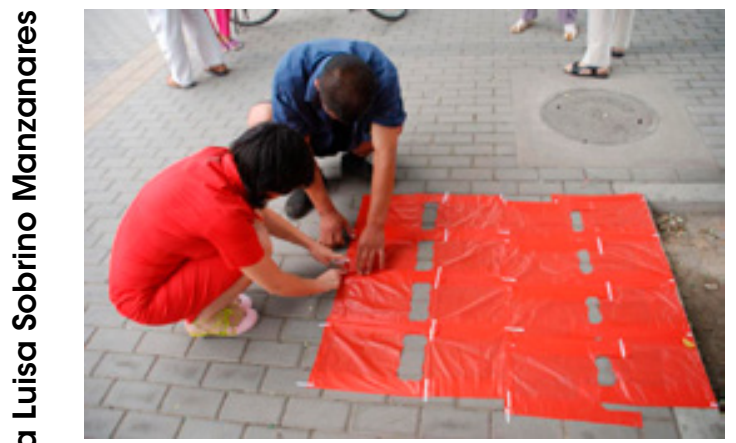

Fig. 25. Carmen Nogueira. Proyecto Próspera Pekín. Site especific

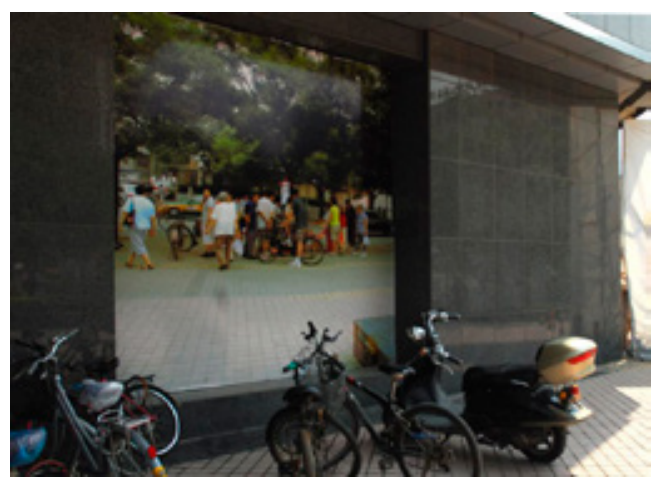

Fig. 26. Carmen Nogueira. Espejo Proyecto Próspera Pekín

nicos: la intervención en la calle (fig. 25), una especie de puesto de venta ambulante (simbiosis de site specific/perfomance) y la proposición expositiva, aunando lo público de las acciones exteriores, con lo privado del lenguaje arquitectónico de los dispositivos en sala, sobre cuyas superficies proyecta fotografías o audiovisuales que recogen imágenes y momentos de esa actuación externa. En el espacio expositivo, los audiovisuales que documentan las acciones de calle en Pekín (fig. 26), y, posteriormente, en Vigo, se presentan enfrentados para marcar los contrastes entre uno y otro espacio, entre el ámbito comunitario oriental y el conflictivo paisaje vigués, como un diálogo entre complementarios.

Este doble momento está presente en muchos de sus proyectos evolutivos desarrollados en el tiempo, como en "Nos camiños" (A trama rururbana), sobre la recuperación de la historia de un barrio vigués de Cabral que expone en una intervención sobre el propio barrio y las salas del CGAC en 2007. Fue realizado, como es frecuente

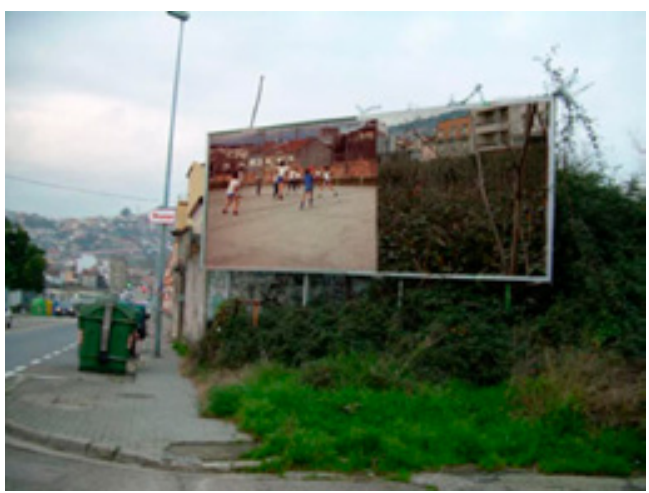

Fig. 27. Carmen Nogueira. Nos Camiños, 2007

en los proyectos de Carme, en colaboración con personas de otras disciplinas -en este caso con la geógrafa María Lois-, alrededor del espacio físico de la antigua fábrica de porcelanas Álvarez que, durante mucho tiempo, fue el centro identitario, físico y económico del barrio. La intervención en el lugar, con carteles (fig. 27), y la presentación de la propia maqueta in situ, sirve para que los vecinos expresen sus recuerdos y sus opiniones sobre la posible reestructuración del barrio (fig. 28). Una maqueta que junto con imágenes del río en cajas de luz y audiovisuales que representan este sentir vecinal, serían luego expuestos en las salas del CGAC (fig. 29). La aportación discursiva de estos videos nos desvela el sentido que sus habitantes memorizan del lugar y sus usos, sus quejas y propuestas ante el abandono que sufre, junto con la evocación de los antiguos itinerarios que habilitaron durante mucho tiempo la unión de ayuntamientos y barrios colindantes, generados por la fábrica, y que nos hablan del río, de los caminos y, al mismo tiempo, expresan una jerarquía: entre el centro y las periferias, categorizando también las actividades a ellos asociadas. Carme recoge estos relatos e indaga los registros sobre los distintos extractos que conforman el paisaje y articularon el barrio y que tienden a desaparecer desde el momento de cierre de esta fábrica que daba trabajo a un importante número de obreras y obreros. El abandono y el cambio de usos será una cuestión que afecta también al paisaje que se vuelve fragmentario y tangencial. En el contexto físico de Álvarez -como señala Carme- lo rural que convivió tanto tiempo con la fábrica, se está transformando en un típico 'rururbano' vigués ${ }^{20}$. 

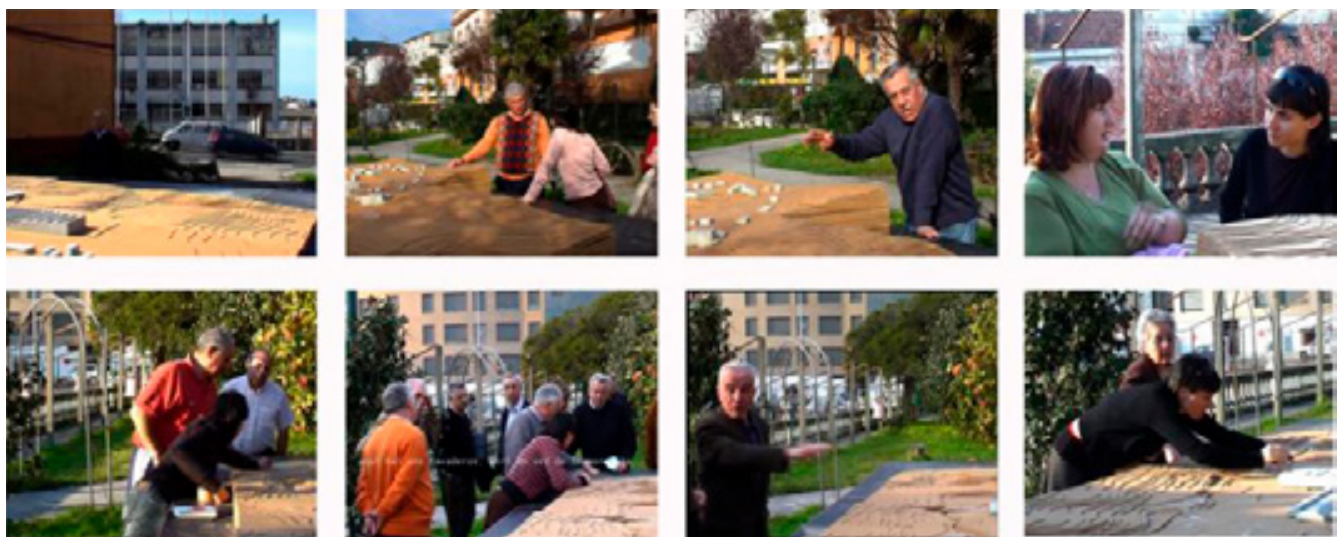

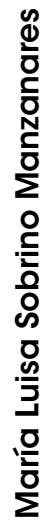

Fig. 28. Carmen Nogueira. Nos Camiños. Vecinos comentando la maqueta (8 fotogramas)

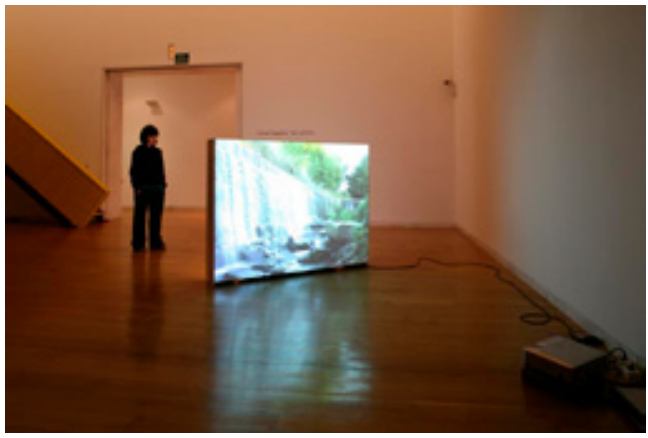

Fig. 29. Carmen Nogueira. Nos Camiños. Caja de luz por detrás

El interés de esta propuesta sobre la rememoración de un antiguo paisaje industrial, activa una de las vías creativas de Carme, que veremos de nuevo en otros proyectos. En 2012, es invitada al ciclo expositivo "La forma y el Querer-decir"21, dentro de un amplio proyecto: Castillete. Retablo minero (El paisaje en desplazamiento I)22, propuesto por el MUSAC para el Laboratorio 987 (fig. 30). Lo más interesante es que se trata de un plan complejo compuesto por muestras expositivas y seminarios interdisciplinares sobre el paisaje del patrimonio industrial de las antiguas explotaciones mineras de la cuenca del Sabero (fig. 31). El proyecto de Carme supone una profunda investigación sobre el territorio y la historia del lugar, reconociendo el terreno en su recorrido, reinterpretando un paisaje donde se superponen formas, miradas y memoria de lo que fue la primera industria minero-siderúrgica del país a principios del siglo XIX. Un auge industrial

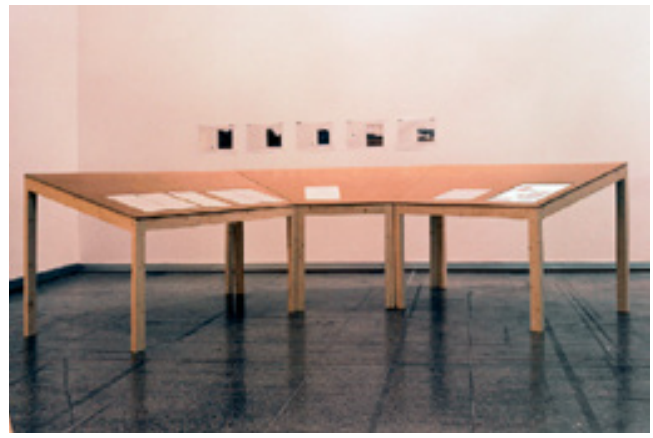

Fig. 30. Display laboratorio. MUSAC

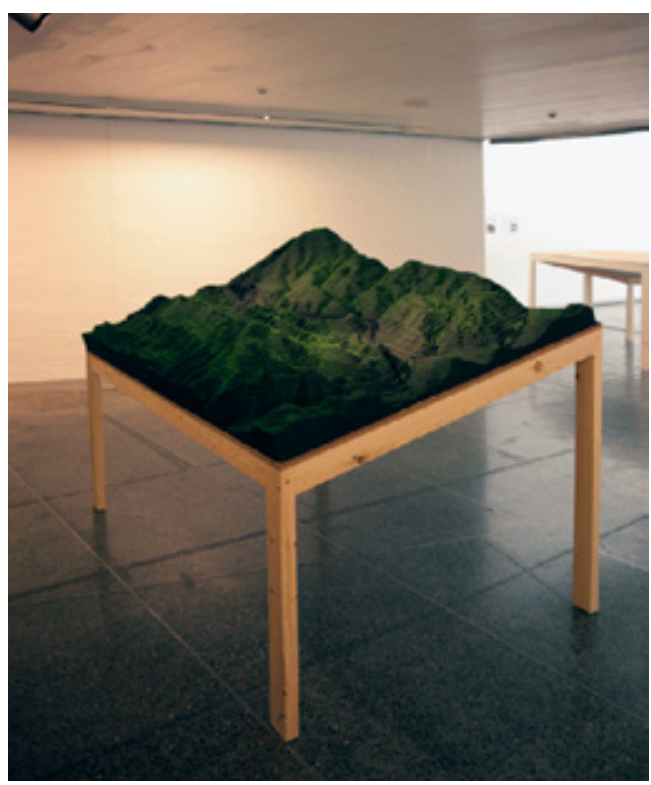

Fig. 31. Maqueta de la exposición. La forma y .. 


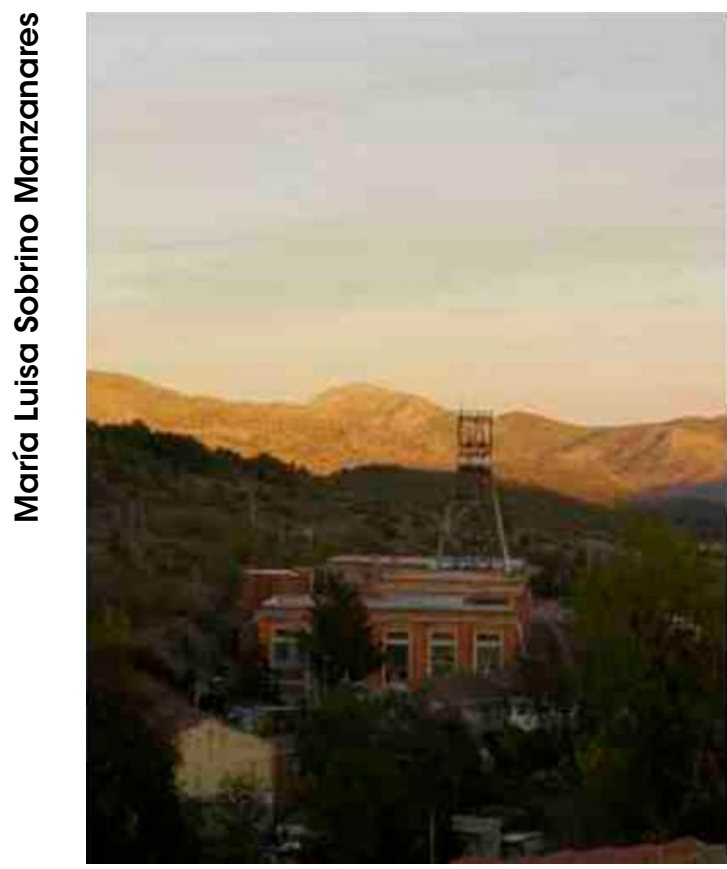

Fig. 32. Carmen Nogueira. Publicación castillete

que supuso el albergue de distintas colonias y comunidades inmigrantes y que fracasaría años más tarde, subsistiendo exclusivamente como explotación minera hasta su cierre definitivo en los años 90. Además de formar parte del trabajo de edición de un facsímil de la revista que lleva el mismo nombre, Castillete ${ }^{23}$, (fig. 32) Carme propone una exposición, concebida como un espacio de representación, una "puesta en relación entre materiales, relatos y registros que conforman las distintas capas sedimentarias ${ }^{24}$. Dispositivos que incluyen una maqueta del territorio, una maquetación audiovisual sobre la memoria, la vida del valle y del pueblo de Sabero, además de los displays funcionales para el desarrollo del seminario. La realización de este proyecto se produce casi sincrónicamente (2012) a las protestas y los conflictos de la minería leonesa, prácticamente en desuso, lo que motivaría sensiblemente a Carme, siempre implicada en este tipo de actuaciones.

Un compromiso que observamos de nuevo en su intervención en el puerto escoces de Leith, con el proyecto "Leith walk. Our share of the profits" sugiriendo a través de sus calles, edificios, vivencias y libros, la historia de este barrio obrero

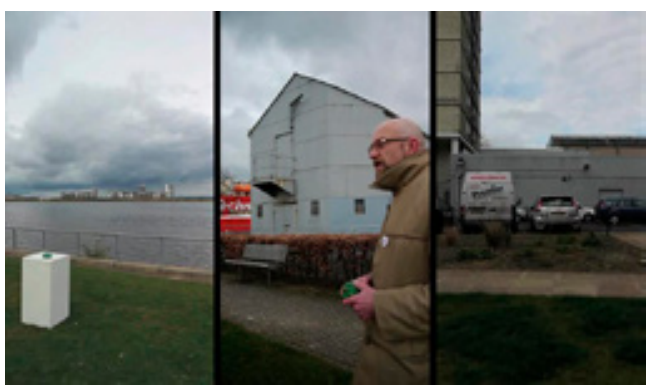

Fig. 33. Carmen Nogueira. Proyecto Leith Walk, 2013

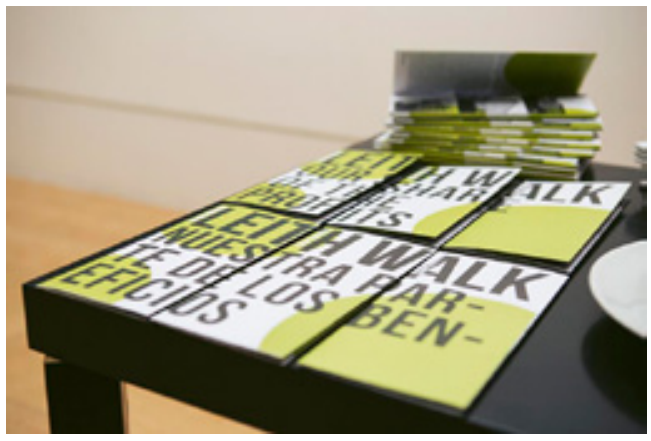

Fig. 34. Carmen Nogueira. Guías del proyecto Leith Walk, 2013

y su reivindicación de los derechos salariales y laborales. Son varios los momentos difíciles, de huelgas, luchas y decepciones a lo largo de un siglo, -desde que en 1913 tuvo lugar la primera huelga-con la perspectiva actual de una amenaza de regeneración de toda la zona y una posible gentrificación proyectada por los recientes planes urbanísticos. Un proyecto de remodelación del barrio a la que sus habitantes se oponen (fig. 33). A manera de un homenaje a esta comunidad, con mínimas intervenciones en tres de sus puntos clave y una documentada guía, Our share of the profits (fig. 34), Carme rememora la historia de este lugar portuario, donde el mantenimiento de su espíritu, a pesar de las alteraciones sufridas en el tiempo, sigue siendo ardientemente defendido por la vecindad que lo habita25.

Ligados a estas propuestas donde lugar y memoria se funden e íntimamente conexionados con ellas, se incluye otra de las directrices del trabajo de Carme ubicada en el corazón de las ciudades, como es la realización de lo que ella misma llama "Los recorridos". Una iniciativa que se enmarca dentro de una serie de actividades ini- 


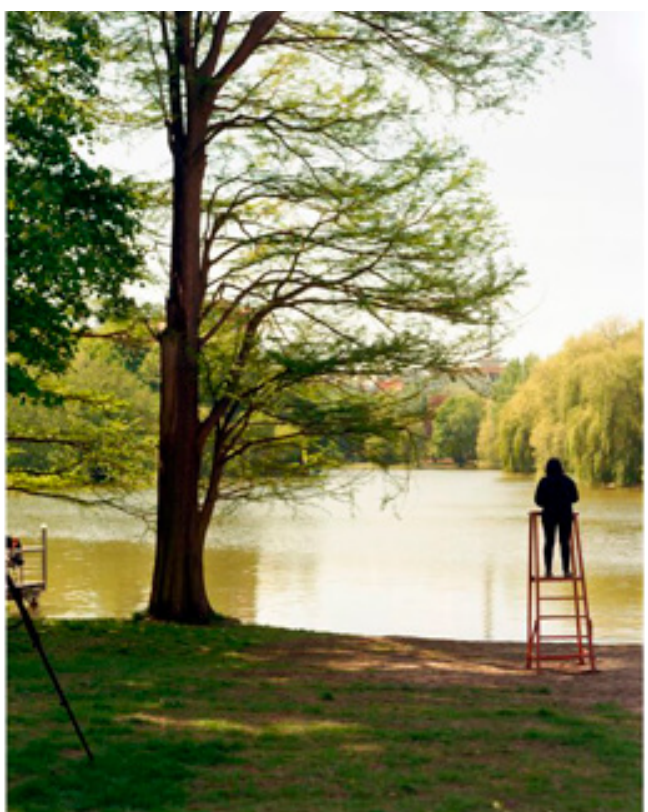

Fig. 35. Carmen Nogueira. Bewegliches Zentrum, Berlin

ciadas en Berlín, "Bewegliches Zentrum (El centro en desplazamiento I)" (fig. 35), realizada durante el verano de 2010, y “El centro en desplazamiento II", ideada para la ciudad de París, en colaboración con Manuel Segade (2011/2013). Bajo la denominación de "La Citoyenneté" realiza una serie de visitas guiadas llevadas a cabo no solamente a través de lugares físicos sino también en aquellos cargados de memoria, adaptados a unas formas de vida y a una historia controvertida.

Como ella misma explica, se trata de aprehender un espacio como vivencia, algo que no es visible ni en los mapas ni en las representaciones icónicas, pero que es lo que realmente rige el espacio como vivencia. "Una de las formas que noté al trabajar en Pekín -indica Carmen- fue la importancia del recorrido en lugar de la abstracción de los mapas, tal y como los veo en la cultura occidental. Para mi esta cuestión es muy importante porque pienso que tiene que ver con el uso y con una idea sobre el espacio público" ${ }^{26}$.

Se trata de una compilación informativa de determinados lugares de la ciudad, recogida en las guías, textos y audiovisuales como resultado de una esmerada investigación acerca da cada sitio. Como señala Manuel Segade, la forma de

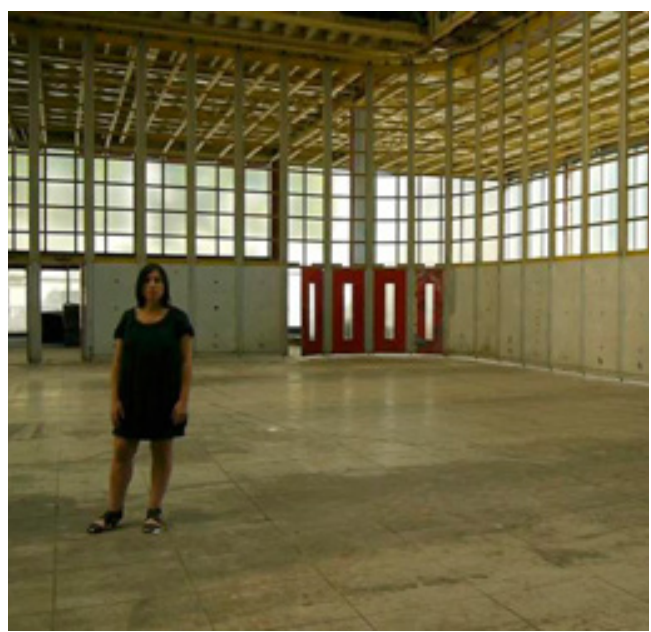

Fig. 36. Carmen Nogueira. Los fines eran triples. La maison du peuple

trabajo de Nogueira puede describirse como "se hace camino al andar", crea una vía diferente de conocimiento del entorno que lleva a reflexionar sobre la especulación urbana o la gentrificación ${ }^{27}$. En esta faceta, ahonda en la memoria de ciertos puntos de la ciudad que han tenido una transcendencia histórica, tanto en el ámbito político, en el social o en cuestiones de género y cuyo recuerdo, solapado para el gran público, permanece vivo -aunque sea lejanamente, como una red de signos- en la propia atmósfera y entre las gentes que habitan esos lugares (fig. 36). Sus armas son la investigación, la documentación y la historia, así como la literatura existente alrededor de los mismos, pero también, la propia gente, el vecindario como sujetos en la construcción del trabajo artístico.

En París, analiza situaciones y lugares, no con los elementos que la configuran y la jerarquizan como la gran ciudad burguesa, ya que no se dirige a los monumentos, ni a bulevares o plazas sino a las fracturas entre las representaciones establecidas y las representaciones emergentes. Por medio de pequeñas guías cuidadosamente diseñadas, con imágenes y textos documentales o con su propia presencia como relatora en audiovisuales, nos acerca a través de una investigación y del dispositivo histórico del discurso a la memoria y al conocimiento sobre la construcción social de determinadas escenas elegidas, para su 


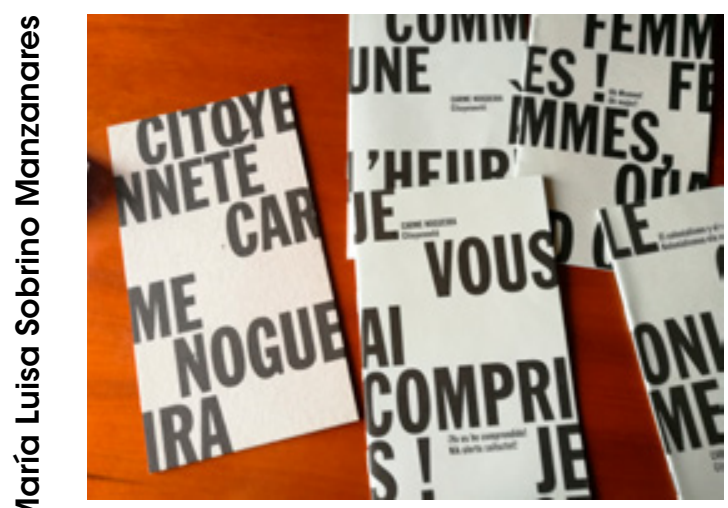

Fig. 37. Carmen Nogueira. Guías de la Citoyenete

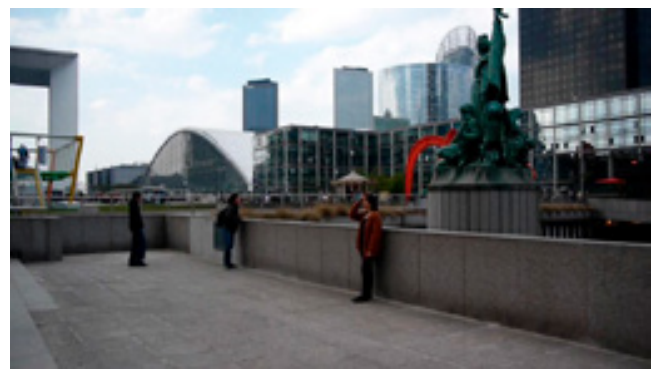

Fig. 38. Carmen Nogueira. La comuna

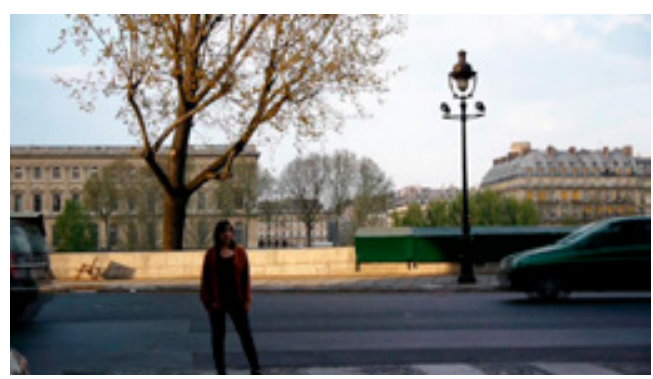

Fig. 39. Carmen Nogueira. Yo os he comprendido. Quai Conti

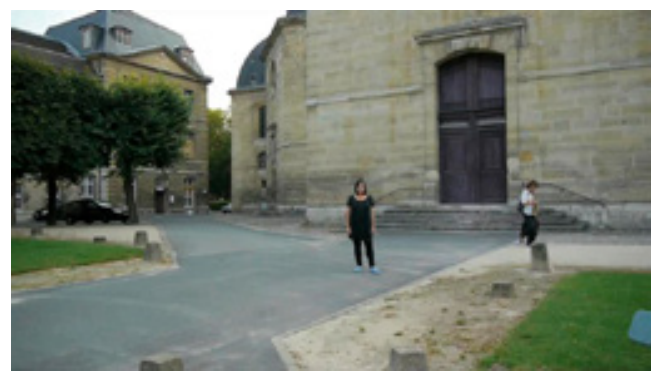

Fig. 40. Carmen Nogueira. ¡Oh mujer mujer! La Salpetrière
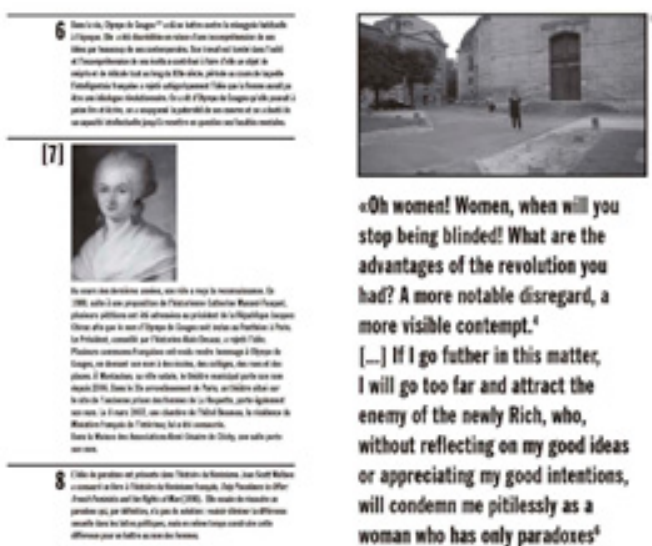

soh momen! Women, whea nill you stop being blinded! What are the aduatages of the revolution you had? A more notatle disregard, a more visiale contempt." [-] If I so father in this mattes, I will go too far and attract the enemy of the nenily Rich, who, without reflecting oa my good ideas or appreciating my good intentions, will condenn me pitilessly as a woman who has caly paradones" to offer and not problems easy to resolve's

Fig. 41. Carmen Nogueira. Carmen Nogueira. Página de la Guía ¡Oh mujer mujer!

intervención (fig. 37). Lugares a los que acude y cuya evocación relata, los irá titulando en su proyecto con las primeras frases de textos referidos a hechos importantes que allí tuvieron lugar, como "La Comuna a esta hora está a punto para la historia" (fig. 38), "Los fines eran triples" para referirse a la Casa del Pueblo de Clychy; las palabras del presidente De Gaulle "Yo os he comprendido", en el histórico Quai Contí, frente al Instituto de Francia o para mostrarnos el edificio de La Salpêtriere (fig. 39), recoge las palabras de la poetisa Olympe de Gouges: ¡Oh mujer, mujer! . "La Citoyenneté" es un conjunto de ocho lugares parisinos, en los que las huellas de un oscuro y problemático pasado sirven para comprender una historia política y social que se irá estratificando hasta el contexto actual (fig. 40).

En los textos y audiovisuales se cuenta lo que ha sucedido, el recorrido que se ha hecho, lo que se ha visto y aprendido, además de un texto "literario" sobre los hechos que allí ocurrieron. Como ella misma afirma en la introducción a estas guías, "se trata de poner al descubierto los discursos con los que se nos ha contado lo visible" (fig. 41).

Carme Nogueira no deja de insistir en un trabajo que pone en evidencia la continua relación interactiva entre el espacio público y su configuración con la idea de ciudadanía. "Paisaje y ciudadanía se relacionan íntimamente: solo por 
medio de un ejercicio más o menos explícito de la ciudadanía se puede construir un espacio social."

Su obra, como intentamos analizar en este texto, se comprende desde la investigación, la acción y la interrogación del territorio, sin descuidar el diálogo con el espacio expositivo. Su apuesta por la intervención temporal, que resulta abierta y siempre participativa, pública, y colaborativa, junto a propuestas que diluyen los límites dentro de la creación artística, la convierten en una artista próxima a formulaciones y estrategias propias de la antropología, el urbanismo o la geografía. Compone una obra pensada en proceso, una puesta en escena donde se fusiona lo documental, la cultura de archivo, el presente, la implicación del público -agente participativo-y las prácticas instaladas. Una producción traducida desde los márgenes y tan pegada a lo social como el propio suelo, la historia, el lugar y sus habitantes, justo donde inserta sus preguntas, sus cuestionamientos, sus prácticas artísticas socialmente comprometidas ${ }^{28}$.

En este contexto quizás podría decirse que el espacio público se ha convertido en un "fuera de campo" del arte, o en todo caso "en un arte que debería cambiar lo que el arte es. Un arte que potencialmente se transforma a si mismo; transforma sus públicos; se permite a si mismo ser transformado por su público; y permite que esas relaciones y definiciones sean transformadas también" 29. 


\section{NOTAS}

1 SOBRINO MANZANARES, María Luisa: Escultura contemporánea en el espacio urbano. Transformaciones, ubicaciones y recepción pública. Editorial Electa España. Madrid. 1999.

2 Cabe señalar que el arte público fue una práctica abierta a implicaciones de otra naturaleza que ponen en tensa dialéctica el valor artístico en sí mismo, con una serie de factores derivados del contexto de lo público: desde las dotaciones económicas del encargo, la pertinencia de la experiencia del lugar tanto en cuanto a su conformación física como en relación a su memoria histórica e igualmente a aquellos que generan las implicaciones urbanísticas del territorio y de la recepción pública. SOBRINO, ob. cit. Pg. 10.

3 HERRÁN, M: Arte público y espacio público. Interferencias en ciudades ajenas. Abriendo la brecha. En "Público", publicado 11/ 03/2014

4 RAMÍREZ BLANCO, Julia: Utopías artísticas de revuelta. Cuadernos de arte Catedra. Madrid. 2014, pg. 19. En esta publicación se estudian muchas de las actividades y acciones creativas de colectivos sociales activistas.

${ }^{5}$ EXPOSITO, Marcelo: "Desobediencia: la hipótesis imaginativa", en Tendencias del arte $y$ arte de tendencia a principios del siglo XXI. Cátedra. Madrid. 2004, pg. 172.

6 KLEIN, Noemí: No logo: el poder de las marcas. Paidós. Barcelona. 2002.

7 HOPE, S. : "Tres por cuatro. Mediciones en el arte socialmente comprometido" texto incluido en la Carpeta editada por Carme NOGUEIRA y Uqui PERMUY : Refuxios. Santiago 2011. En esta carpeta se contienen varios folletos y guías, dispositivos en papel, cuidadosamente elaborados por las propias artistas con textos y fotografías, que se conciben como parte de la propia obra. No se imprimen como forma comercial, ni bibliográfica.

8 LACY, S: "Debated territory: Toward a Critical Language for Public Art", en S.
LACY (ed.), Mapping the Terrain. Seatle: By Press, 1994.

9 RAMÍREZ BLANCO, Julia: "Los descampados de promisión de Lara Almarcegui" en Quintana, Revista del Departamento de Historia del Arte. $\mathrm{N}^{\circ}$ 11, 2012, pg. 237.

${ }^{10}$ NOGUÉ, J. (ed): La construcción social del paisaje. Biblioteca Nueva. Madrid. 2007, pg. 10

${ }^{11}$ NOGUEIRA, Carme: "Metrónom" en Refuxios. Carpeta citada.

${ }^{12}$ Este proyecto, realizado en Santiago de Compostela, encargado por el Centro Galego de Arte Contemporánea (CGAC) en 2007 consistió, por una parte, en invitar al público a visitar el gran descampado de Fontiñas. Se trata de una zona al norte de la ciudad, de 44.500 metros cuadrados que aún quedaba en estado salvaje a punto de desaparecer para ser edificado y transformado en parque. La parte de este proyecto tendría lugar en el patio posterior del CGAC, integrado en el parque de Bonaval. Aquí, por el contrario, su acción consistió en levantar y excavar el suelo de uno de los patios incluidos en la propia arquitectura del edificio del museo, para descubrir el descampado que existía en su origen. Folleto editado por el Centro Galego de Arte Contemporánea. Folleto sin fecha.

${ }^{13}$ RAMíREZ BLANCO, Julia: "Los descampados de promisión de Lara Almarcegui" en Quintana. Revista del Departamento de Historia del Arte. Ob cit. pg. 234.

${ }^{14}$ SEGADE, M: Refuxios. Catálogo. "Metrónom" .Barcelona. 2005.

${ }^{15}$ VILA-MATAS, E.: Kassel no invita a la lógica. Seix Barral. Barcelona 2014. Pg.137

${ }^{16}$ NOGUEIRA, Carme: La representación como puesta en escena. Para una teoría de la mirada. Diputación de Valencia. Valencia. 2001.

${ }^{17}$ OLVEIRA, Manuel: "Reconstrucción de un contexto", Catálogo Nos Camiños. CGAC. Santiago de Compostela. 2008. Pg. 22.
${ }^{18}$ NOGUEIRA, C. Refuxios. Carpeta cit

${ }^{19} \mathrm{El}$ primero pertenece al proyecto integrado en "A cidade interpretada", una exposición urbana comisariada por Pablo Fanego en Santiago en 2006. El proyecto de Oporto, realizado entre 2016-17, reúne una serie intervenciones en homenaje a la memoria del antiguo pabellón de la "Ferreiriña" de la Exposición Colonial de 1934, y que titula genéricamente "A propósito de Alvao". En ambos se propicia el dar voz a estos colectivos ciudadanos que actúan como agentes capaces de elaborar desde la teoría y la praxis, alternativas, resistencias y propuestas creativas, frente a modelos sociales jerarquizados $y$ excluyentes.

${ }^{20}$ Véase el Catálogo Nos Camiños. CGAC . Santiago de Compostela .2008

${ }^{21}$ Exposición comisariada por Leire Vergara.

${ }^{22}$ Acciones llamadas así por Carme porque suponen un recorrido, un desplazamiento del cuerpo.

${ }^{23}$ Editada y diseñada por Carme, Leire Vergara y Uqui Permuy.

${ }^{24}$ Editorial de la revista Castillete, pg. 3. MUSAC. León. 2013.

${ }^{25}$ Como señala la comisaria de esta exposición, Ana González Chouciño, en el dispositivo realizado para este proyecto, "Leith walk. Our share of the profits" : la historia de este barrio, contada ahora desde el presente: luchas, victorias y decepciones, es un homenaje a sus vecinos, que han conseguido mantener el espíritu de Leiht, tan cerca y tan lejos del resto de Edimburgo. Folleto editado a raíz de este proyecto.

${ }^{26}$ NOGUEIRA, C., "Recorrer", en Refuxios. Carpeta cit

${ }^{27}$ SEGADE, M.: Refuxios. Catálogo "Metronom " cit

${ }^{28}$ Son numerosas las diferentes intervenciones de Carmen, recogidas en www.cntxt.org

${ }^{29}$ HUTCHINSON, M: Four stages of Public Art. Thir Text, vol. 16, num. 4. 2002, pp. 329-438. 


\section{REFERENCIAS}

Blanco, A., and J. Carrillo, eds. 2001. Modos de hacer. Arte crítico, esfera pública y acción directa. Salamanca: ediciones de la Universidad de Salamanca.

Nos camiños. 2008. Catálogo Exposición. Centro Galego de Arte Contemporánea. Santiago de Compostela: CGAC.

Carrillo, J., and L. Bravo, eds. 2004. Tendencias del arte, arte de tendencias a principios del siglo XXI. Cuadernos de Arte Cátedra. Madrid: Cátedra.

Culture in action. 1995. Exhibition Catalogue. Seattle: Bay Press.

Expósito, Marcelo. 2004. "Desobediencia: la hipótesis imaginativa." In Tendencias del arte y arte de tendencia a principios del siglo XXI. Madrid: Cátedra.

Herrán, M. 2014. "Arte público y espacio público. Interferencias en ciudades ajenas. Abriendo la brecha." Público, Marzo 11, 2014.

Hutchinson, M. 2002. "Four stages of Public Art." Thir Text, vol. 16, no. 4: 329-438. https:// doi.org/10.1080/0952882031000077666

Klein, Noemí. 2002. No logo: el poder de las marcas. Barcelona: Paidós.

Lacy, S. ed. 1994. Mapping the Terrain. Seattle: By Press.

Lacy, S. 2010. Leacing Ar. Seattle: Duk Press. https://doi.org/10.1215/9780822391227
Lippard, L. 2004. Seis años: La desmaterialización del objeto artístico. De 1966 a 1972. Akal. Arte Contemporáneo. Madrid: Akal.

Nogué, J. ed. 2007. La construcción social del paisaje. Madrid: Biblioteca nueva.

Nogueira, C. 2001. La representación como puesta en escena. Para una teoría de la mirada. Valencia: Diputación de Valencia.

Oldenburg, Wendelien van. 2010. A well respected man. Venezia: Casco.

Olveira. M., 2008. "Reconstrucción de un contexto." In Nos Camiños. Santiago de Compostela: CGAC.

Ramírez Blanco, J. 2012. "Los descampados de promisión de Lara Almarcegui." Quintana. Revista de estudios del Departamento de Historia del Arte 11: 231-241.

Ramírez Blanco, J. 2014. Utopías artísticas de revuelta. Cuadernos de Arte Cátedra. Madrid: Cátedra.

Segade, M. 2005. Refuxios. Barcelona: Metrónom.

Sobrino Manzanares, Mª L. 1999. Escultura contemporánea en el espacio urbano. Transformaciones, ubicaciones y recepción pública. Madrid: Electa.

Vila Matas, E. 2014. Kassel no invita a la lógica. Barcelona: Seix Barral.

Wade, Gavin, and C. Condorelli. 2009. Support Structures. Berlin: Sternberg Press. 
